\title{
Algumas reflexões acerca da Constituição como lei fundamental do direito civil ${ }^{*}$
}

\author{
Carmem Lúcia Silveira Ramos**
}

\begin{abstract}
Sumário:1. Do Código Civil à Constituição; 1.1 Os alcances e paradoxos do sistema jurídico;1.2 A superação da ideologia consagrada no Código Civil; 2. Relevância e Ineficácia do Regramento Constitucional; 2.10 mito da ineficácia do regramento constitucional; 2.2 A auto-aplicabilidade das normas constitucionais; 3. Mudança e Transformação na Função da Constituição; 3.1 A superação do sistema clássico e o fim do dogma da autonomia privada; 3.2 A ordinarização da Constituição; 4. Bibliografia.
\end{abstract}

\section{Do Código Civil à Constituição}

\subsection{Os alcances e paradoxos do sistema jurídico}

Superada a teoria pura do direito, na segunda metade do século XX gradativamente se observa a queda do mito da neutralidade na análise da construção jurídica. ${ }^{1}$

Contestado o lado mistificador de um direito centrado em si mesmo, divorciado da realidade social, passa a ser reconhecida a influência recíproca entre os aspectos sociais, econômicos, antropológicos,

* Ensaio teórico apresentado à disciplina Direito Civil e sociedade, ministrada pelo Professor Doutor Luiz Edson Fachin.

** Doutoranda em Direito das relą̧ões sociais da Universidade Federal do Paraná, Professora de Direito Civil da Faculadade de Direito da UFPR. Advogada.

1 Sobre a impossibilidade de neutralidade científica em matéria de ciências sociais, escreveu Paulo Ferreira da Cunha: "E, quer se queira, quer não, o mundo político e ideológico não é nunca o reino da Razão, mas da imaginação, da paixão, da irracionalidade. Em grande medida, o mundo do mito." (in Sociedade e Direito - Quadros institucionais. Porto, RÉS-Editora, p. VII).

Também a propósito do apelo aos mitos pelo direito, cabe citar Maurice Gaillard: "En tant que moyen de régulation primordial des relations sociales, le droit ne pouvait qu'offrir un terrain privilégié à cette pénétration des mythes. Et, de fait, la mythologie juridique est opulente." (in L'intelligence du droit. Paris, Les Éditions d 'Organisation, 1992, p. 75).

Revista da Faculdade de Direito da UFPR, Curitiba, a. 29, n. 29, 1996, p.147-172 
psicológicos, políticos, dentre tantos, e os fenômenos normativo-jurídicos, no sentido de que a transformação de uns provoca a modificação dos outros.

A perspectiva do direito, baseada nas idéias do liberalismo, se revela, no entanto, e até hoje, antropocêntrica, no sentido individualista, o que conduz a reflexões acerca de sua superação.

Partindo a redação e fundamentos das normas jurídicas das idéias do individualismo, a interpretação e aplicação dos direitos consagrados no sistema jurídico eventualmente contraria princípios da sociologia, da economia, bem como leis da biologia, da química, da física e de outras ciências, sociais e da natureza.

Segundo a visão da pandectística alemã, o homem, como sujeito de direito, é o elemento chave das relações jurídicas.

Não se atribui dignidade jurídica aos bens e coisas, enquanto objetos de direito.

Daí o paradoxo e a pretensão de superação deste antropocentrismo, em nome da preservação dos interesses da humanidade, da proteção da própria vida no planeta Terra.

Na passagem da noção tradicional de direitos do homem, num sentido de direitos individuais, para a de cidadania ${ }^{2}$ situa-se um dos aspectos desta nova construção jurídica.

O cidadão, enquanto pessoa, embora corresponda a uma individualidade, passa a ser considerado em seu conjunto, na sua participação como agente econômico, como ser político, no seu status profissional e familiar, enfim, como um elemento do construído que é a história da humanidade.

Neste sentido, a proteção dos direitos fundamentais passa do estatuto privado para um estatuto de natureza sócio-política, repersonalizando-se as categorias consideradas fundantes da ordem jurídica, a partir do estabelecimento de novos paradigmas. ${ }^{3}$

2 A noção de cidadão é tomada “em sua dimensão dialética, para identificar o sujeito, aquele ser responsável pela história que o envolve. "(CLÈVE, Clémerson Merlin, in Temas de Direito Constitucional (e de Teoria do Direito). São Paulo, Editora Acadêmica, 1993, p. 16)

3 “Famille, propriété, contrat, sont, de tradition, les trois piliers de l'ordre juridique." (CARBONNIER, Jean, in Flexible droit - Pour une sociologie du droit sans rigueur, 7. e.d. Paris, Librairie Générale de Droit et de Jurisprudence, 1992, p. 200). 
Assim é que, na passagem de um direito de conotação eminentemente individualista para a proteção cada vez maior dos interesses coletivos, a propriedade imobiliária é funcionalizada, no sentido de cumprir e atender a finalidades de cunho social, restringindo os direitos antes praticamente absolutos do proprietário, embora tenham sido preservados os meios de apropriação particular dos bens.

A família, de instituição privada, passa a um direito do cidadão, assumindo uma pluralidade de feições, afastada a família matrimonializada como sua forma única, envolvendo mais uma união de afeto e menos uma forma de perpetuação das relações de produção e de aquisição e preservação do patrimônio.

Dá-se a superação do modelo clássico de contrato, cujo pressuposto era a igualdade formal das partes, deixando ele de ser um ato de autonomia privada, ao menos em caráter de exclusividade. A política intervencionista estabeleceu uma série de limitações à liberdade das partes, de que é exemplo significativo o contrato de trabalho, no qual as cláusulas enxertadas estabelecem direitos para o trabalhador, e limitam os poderes do patrão sobre o empregado.

A função do direito na sociedade pode assumir duas faces: (I) manutenção do status quo; (II) transformação (função promocional, na expressão de Norberto Bobbio).

Qual seja, o direito é, simultaneamente, fator condicionado e condicionante dos fatos econômico-sociais, da realidade complexa de que é historicamente parte integrante. ${ }^{4}$

$\mathrm{Na}$ mesma linha de pensamento, se o direito posto traduz o interesse na preservação de um determinado modo de produção e de certas estruturas sociais, este mesmo direito dominante submete-se a um confronto com os valores e interesses da sociedade em mutação, que conduzem à sua alteração.

Por outro lado, do ponto de vista de sua estrutura interna, o direito se organiza em sistema jurídico, de caráter unitário e harmônico, de tal sorte que as alterações nele inseridas, a partir da edição de uma norma ou de um conjunto de regras, afeta a leitura e a individualização das normas precedentes e das subsequentes.

4 PERLINGIERI, Pietro. Profili istituzionali del diritto civile. Camerino, Jovene editore, 1975, p. 4.

Revista da Faculdade de Direito da UFPR, Curitiba, a. 29, n. 29, 1996, p. 147-172 
A Constituição Federal, por traduzir a ideologia de um determinado contexto histórico-político, coloca-se numa posição de preeminência dentro do sistema jurídico, devendo ser considerada o documento por excelência para dirigir a leitura e interpretação das regras relativas às relações jurídicas em geral e às relações jurídicas de direito civil em particular.

Ainda que contenha paradoxos e contradições, por ser, ante a diversidade de correntes de pensamento que orientam sua redação o documento que, em termos de direito vigente (ou de direito imposto) melhor traduz o contexto interdisciplinar da nação politicamente organizada, os princípios e normas contidos na Constituição devem ser reputados de fundamental importância para a interpretação das regras relativas às relações privadas.

Estas observações partem de uma visão interdisciplinar do direito, tanto intrasistemática, no sentido de que acabam por conduzir à conclusão de que todo o direito visa proteger simultaneamente interesses públicos e privados, quanto externamente ao sistema, na medida em que acolhem sua vinculação com a realidade, com a estrutura organizacional da sociedade na qual se encontra inserido.

O objetivo desta leitura é evitar um divórcio entre este direito imposto e a realidade.

Exemplificativa a propósito é a necessidade da aplicação das normas e princípios constitucionais relativos à proteção do meio ambiente pelo Poder Judiciário (o que é fundamental para um país com a extensão territorial do Brasil), objetivando evitar a exploração descontrolada de seus recursos pelo homem, promovendo o controle do impacto ambiental, buscando o equilíbrio da natureza, de modo a conciliar os direitos do homem e aqueles que Antonio Tarantino designou direitos da humanidade, buscando o equilíbrio ecológico, retomando a ordem natural das coisas no sentido de considerar a Terra como um organismo vivo, que como tal deve ser preservado. ${ }^{5}$

5 A propósito de progresso científico e seus perigos, Antonio Tarantino contrapõe os direitos do homem e a irresponsabilidade da comunidade científica em matéria da proteção do meio ambiente, em nome da prevenção do que chama de "vingança da natureza" - consequência dos danos irreparáveis a ela infringidos - propondo seja substituida esta atitude de descaso pela noção de direitos da humanidade. Segundo ele, assim se poderia obter uma evolução harmônica do progresso humano, estabelecendo a linha ao longo da qual deveria se desenvolver a tutela dos direitos humanos (conciliados com os direitos da humanidade) e o programa do progresso científico (in Diritti umani, progresso cientifico e tutela dell'ambiente, in LIPPOLIS, Laura (org.). Diritti umani, poteri degli stati e tutela dell'ambiente. Milano, Giuffrè, 1993, p. 127). 
Neste sentido, a apropriação passa a ser vista como ligada à consciência ecológica, a partir do reconhecimento de que a natureza também tem direitos e que a preservação da vida humana na face da Terra não apenas está ligada, mas depende da proteção ambiental.

Os alcances, incoerências e paradoxos do sistema jurídico são questionados pela própria sociedade, como o são pelos operadores do direito, levando a crítica do conhecimento jurídico para além dos textos dos doutrinadores e para fora das universidades, objetivando-se com isto evitar a contínua reprodução das relações sociais dominantes, na busca de novas soluções, no que há que se ter, no entanto, a cautela de evitar substituir os antigos por novos mitos, simplesmente repetindo o passado, risco ao qual, diga-se de passagem, não há como fugir.

\subsection{A superação da ideologia consagrada no Código Civil}

O Código Civil Brasileiro em vigor foi redigido sob a influência de idéias individualistas, de conotação positivista, prevalentes ao final do Século XIX.

Presente em seus dispositivos está o mito da neutralidade do Estado liberal, a visão do interesse público apenas como a forma de se assegurar melhores condições para o exercício e o desenvolvimento dos direitos privados. civil.

Trata-se de uma codificação redigida para regular a vida da sociedade

A passagem do tempo trouxe consigo novos paradigmas, alterando os dados contidos no Código, o que o torna ideologicamente superado. em face da Constituição Brasileira de 1988, senão por qualquer outra razão, pelo momento histórico mais atual em que foi editado o texto constitucional.

Uma primeira referência, a propósito, é a crítica à abstração e ambiguidade da noção de pessoa, como sinônimo de sujeito de direito, por seu artificialismo, por ser insuficiente para explicar a realidade, bem como por sua função na sociedade liberal-burguesa, no sentido de que não se trata de uma noção natural, mas jurídico-ideológica, surgida historicamente 
como efeito da estrutura social capitalista, ${ }^{6}$ e trabalhada com o intuito de ser ligada à idéia de liberdade do indivíduo.

Denota também claramente este aspecto a diversidade de tratamento entre o ter e o ser nos dois textos: enquanto o Código Civil consagra um direito de propriedade típico do liberalismo individualista do século XIX, a propriedade constitucional é funcionalizada, no sentido dos valores sociais e existenciais; do estatuto privado da pessoa e da família no Código Civil de origem burguesa, passou-se na Constituição ao estatuto sócio-político do cidadão e à repersonalização da família, na sua pluralidade de configurações.

Especificando melhor: na categoria do ter, em matéria de apropriação de bens, enquanto o Código Civil é um ordenamento da propriedade privada, em que apenas a apropriação individual é considerada e que inclusive coloca a propriedade imobiliária numa situação hierarquicamente superior à mobiliária, como resíduo histórico, em que as relações de família estão permeadas com a preocupação de garantir, a partir da hierarquia interna e do casamento indissolúvel, a higidez do patrimônio familiar, subordinando neste sentido o ser ao ter, a Constituição Federal, ao garantir o direito de propriedade delimita que a propriedade atenderá à sua função social, e, assim considerando, supera a relação tradicional homem-coisa. ${ }^{7}$ Ao mesmo tempo, em matéria de família, faz uma opção pela igualdade substancial e pela afetividade.

Ademais, na categoria do ser, a Constituição consagra expressamente a proteção dos direitos fundamentais do ser humano: igualdade substancial, dignidade, vida, honra, de sorte a ensejar uma releitura das normas de direito privado a respeito da pessoa, uma vez que a categoria jurídica sujeito de direito foi introduzida no Código Civil a partir de uma concepção meramente virtual, divorciada da realidade.

6 A propósito, escreveu Michel Miaille: “O modo de produção capitalista supõe, pois, como condição do seu funcionamento a "atomização", quer dizer, a representação ideológica da sociedade como um conjunto de indivíduos separados e livres. No plano jurídico, esta representação toma a forma de uma instituição: a do sujeito de direito", (in Introdução crítica ao direito. Lisboa, Editorial Estampa, 1989, p, 118).

7 Neste passo, a propriedade passa a ser "una situazione giuridica soggettiva tipica e complessa", como refere Gustavo Tepedino, que complementa: "Tale argomentazione capovolge, in effetto, la tradizionale elaborazione concettuale che, comè noto, ravvisa nella proprietà una relazione tra soggetto e oggetto, caratteristica tipica della definizione di diritto reale assoluto (o pieno), espressione della "massima signoria sulla cosa"; nozione che, coerentemente, non può non ribellarsi all'idea di relazione intersoggettiva. "(in Contorni della proprietà nella Costituzione brasiliana del 1988 Rassegna di diritto civile, diretta da Pietro Perlingieri. Edizioni Scientifiche Italiane, 1/91, p. 108-9) 
Em resumo: no Estado intervencionista, o direito civil, como garantia da esfera do privado, muda de função.

No Século XIX, havia uma clara delimitação do âmbito do direito público e do direito privado; a separação entre as esferas da sociedade civil e do Estado (que não interferia na atividade privada) era muito nítida.

Os institutos fundamentais do direito privado - a família, a propriedade, o contrato - eram vistos como tradução do exercício da autonomia privada, da liberdade dos cidadãos, afastando qualquer espécie de intervenção do poder público. ${ }^{8}$

A ficção da igualdade formal dos sujeitos, a garantir a isonomia de todos perante a lei, mas não a paridade de forças econômicas e na sociedade, rapidamente se revelou terreno fértil para as desigualdades de fato.

O direito civil burguês acolhia e reforçava estas desigualdades de fato, v.g. garantindo ao operariado, no âmbito de sua autonomia privada, vender sua força de trabalho, mas apenas isto, de tal sorte que, relativamente à fábrica e à oficina ele era, na verdade, objeto de produção; tutelando a propriedade individual de conotação quase absoluta; garantindo a liberdade ampla de ação dos detentores do poder econômico.

Em virtude disto, as reivindicações sociais começaram a se fazer cada vez mais presentes já durante o século XIX e, no início do século XX, o Estado começou gradativamente a acolhê-las, senão porque fosse sensível aos reclamos da comunidade, pela própria pretensão de manter o status quo em termos de estrutura de poder.

O mecanismo adotado para tanto passou pelo abandono de sua posição de neutralidade por parte do Estado liberal, que começou a interferir na atividade dos particulares, seja controlando, seja impondo limites a suas ações, ou interferindo diretamente no processo de produção e distribuição de riquezas.

O fenômeno da intervenção do Estado na economia e na vida do cidadão, numa sequência gradativa, se fez cada vez mais presente, ainda

8 A propósito, referiram E. ROPPO.e M. SCAPARONE: "Il diritto privato è, in questa fase, un territorio precluso agli interventi dell'autorità politica; i suoi istituti fondamentali - famiglia, testamento, proprietà, contratto - esprimono l'esaltazione della libertà dei privati cittadini, sono altrettanti baluardi che la presidiano contro l "ingerenza dei poteri pubblici." (in Diritto pubblico e diritto civile. Bari, Editori Laterza, 1985, p. 319).

Revista da Faculdade de Direito da UFPR, Curitiba, a. 29, n. 29, 1996, p. 147-172 
que tal intervenção se dê e ocorra cada vez mais através da utilização de instrumentos e institutos próprios do direito privado, de que é característica a política intervencionista nos contratos.

Assim é que, à medida que se questiona a capacidade do poder público de atuar com eficiência no exercício de determinada atividade econômico-produtiva, instituições privadas são chamadas a se instalar em setores controlados pelo Estado, no processo denominado privatização. ${ }^{9}$

De outra parte, pelo dirigismo econômico o conteúdo do contrato saiu do âmbito exclusivo da autonomia privada, reconhecendo-se, a partir daí, a superação da igualdade formal no plano da realidade. ${ }^{10}$

Não há como se deixar de destacar, neste passo, a capacidade de adaptação e flexibilização da família, da propriedade e do contrato, no sentido de sua sobrevivência através do tempo, a partir da alteração de seu perfil, adaptando-se às mudanças de sistema político-econômico.

Se à luz de uma economia liberal e capitalista, a ordem jurídica burguesa consagrava uma propriedade eminentemente individual, hoje a propriedade continua sendo garantida aos cidadãos, porém funcionalizada para os interesses sociais; se o contrato era, do ponto de vista da ordem jurídica individualista, o instrumento por excelência do exercício da autonomia privada, agora o dirigismo contratual estabelece limitações à sua prática, interferindo nos ajustes; se a família hierarquizada e patrimonializada era característica da sociedade do século XIX, o interesse na preservação da família nuclear tornou-a igualitária, pluralizada e um núcleo de afeto suscetível de proteção pelo conjunto da sociedade.

9 É característico deste movimento o que ocorre atualmente no Brasil com a quebra do monopólio estatal em atividades como a de telecomunicações e exploração do petróleo, dentre outras.

A questão envolve controvérsias, tanto no âmbito ideológico, quanto na sua forma operacional, como se depreende da crítica de Giorgio Oppo à utilização das sociedades por ações para fins diversos de sua função típica na privatização em curso na Itália (in Diritto privato e interessi pubblici. Rivista di diritto civile. Padova, CEDAM, Ano XL (1), gennaio-febbraio 1994, p. 40).

10 Orlando Gomes afirmou, a propósito: “A igualdade formal falhou na prática. O contrato passou a ser arma de exploração do mais fraco pelo mais forte obrigando a uma política legislativa de tratamento desigual para restaurar o equilíbrio entre as partes. Foi preciso compensar a inferioridade econômica dos pobres com uma superioridade jurídica, limitando a liberdade de contratar e usando a técnica de determinar imperativamente o conteúdo de certos contratos. Tornou-se assim evidente a necessidade de um direito desigual. " (in Transformações gerais do direito das obrigações, 2.ed. São Paulo, Ed. Revista dos Tribunais Ltda., 1980, p. 72). 
Neste processo histórico, com seus componentes ideológicos, com suas causas e consequências econômico-sociais, permeado de dados científicos e culturais, afetado pela antropologia, pela psicologia, dentre tantos outros elementos, não apenas se transformaram os institutos fundamentais do direito privado, mas alterou-se o perfil e os próprios limites entre o direito público e o direito privado.

Os novos paradigmas nas noções de família, de apropriação e de contrato foram basicamente inseridos através de disposições constitucionais, afetando as disciplinas jurídicas em geral e o direito privado em particular, resultado que são da circunstância de refletirem a concepção da vida da sociedade, com as inspirações mutidisciplinares que sofreu, e, embora ainda mantenham, como princípio, um direito centrado no homem, contêm restrições e limites derivados da preservação dos interesses coletivos, ausentes no sistema clássico do direito civil. ${ }^{1}$

Como consequência disto, hoje é difícil encontrar um interesse privado completamente autônomo, independente, que possa ser exercido com exclusão do interesse público ou coletivo.

Se é difícil sustentar que um interesse é exclusivamente particular, no sentido oitocentista do termo, conforme consagravam as codificações de direito civil, inclusive a brasileira, também é fato que não há como se falar em interesse público puro e simples, uma vez que este é (ou deve ser) sempre funcionalizado no sentido da realização dos direitos dos cidadãos.

Isto é muito patente nas antes referidas instituições reputadas fundamentais na ordem jurídica: na funcionalização da propriedade, na

11 A respeito do fenômeno no direito francês, escreveu François Luchaire, :"Le droit constitutionnel pénètre aujourd'hui dans toutes les disciplines juridiques et par conséquent dans le droit civil. " (in Les fondements constitutionnels du drois civil. Revue trimestrielle de droit civil. Paris, (2), avril-juin 1982 , p. 249), explicitando adiante, a respeito das normas constitucionais consagradoras dos direitos e liberdades da pessoa humana: "Une certaine conception de la vie en société est à la base des normes constitutionnelles ainsi comprises; cette conception s'explique elle-même par deux inspirations principales: l'une provient de la philosophie individualistte de 1789; l'autre provient de la philosophie plus socialiste de 1946; sur certains points d'ailleurs le préambule de 1946 et le texte même de la Constitution de 1958 obligent à écarter certaines dispositions de la Déclaration de 1789 ou à l'interpréter autrement qu'à l'époque révolutionnaire; quant aux principes fondamentaux reconnus par le lois de la République ou bien ils remontent à la période révolutionnaire ou bien ils se situent entre ces deux philosophies car ils consacrent des droits qui prolongent ceux reconnus en 1789 mais qui s'expriment collectivement. “ (p. 252)

Revista da Faculdade de Direito da UFPR, Curitiba, a. 29, n. 29, 1996, p. 147-172 
repersonalização da família no texto constitucional, ${ }^{12}$ e nas normas relativas aos contratos, objetivando a proteção da parte economicamente mais fraca.

\title{
2. Relevância e Ineficácia do Regramento Constitucional
}

\subsection{0 mito da ineficácia do regramento constitucional}

\author{
A doutrina tradicional, refletindo os princípios da Revolução
} Francesa e a concepção do contrato social, atribuia à norma constitucional a natureza de norma programática, relevante do ponto de vista ideológico-político, mas não sob o prisma normativo. ${ }^{13}$

Isto nada mais é do que a consequência da visão do liberalismo oitocentista, que concebia o Estado de Direito como voltado apenas para a proteção da ordem jurídica, não interferindo nas atividades da sociedade civil. $^{14}$

Neste sentido, prevalecia nas constituições liberais uma concessão formal do poder, exercida através do aparato do Estado, para a garantia da

12 Em "A repersonalização das relações de família", Paulo Luiz Neto Lôbo refere que "A restauração da primazia da pessoa, nas relações de família, na garantia da expressão da afetividade, é a condição primeira de adequação do dị̣eito à realidade." (in O direito de família e a Constituição de 1988, Carlos Alberto Bittar (Coordenador). São Paulo, Saraiva, 1989, p. 72). Complementando, adiante, a propósito da família como "espaço de realização pessoal afetiva, despatrimonializada": "A repersonalização de suas relações revitaliza a união familiar, em todas as suas manifestações sociais e não apenas a oficial, que renasce com outros fundamentos." (op. cit., p. 74).

13 "A Constituição traduzia, por um lado, a forma de organização do poder político, definindo os limites à actividade do Estado, e garantia, por outro, aos cidadãos um conjunto de direitos contra aquele, isto é, constituía o estatuto da defesa da sua esfera de liberdade perante o Estado." Daí que a Constituição fosse, não a lei fundamental da ordem jurídica de uma colectividade politicamente organizada, mas sim e apenas o estatuto da organização política da sociedade. (Ana Prata, in A tutela constitucional da autonomia privada. Coimbra, Livraria ALMEDINA, 1982, p. 32-3).

14 Segundo Francesco Galgano, "Dalla fine del Settecento, quando ha inizio il processo di costituzionalizzazione [ 1.3.], fino al principio del Novecento l'idea di costituzione aveva espresso, fondamentalmente, l'opposizione della società borghese al dispotismo politico: le costituzioni liberali avevano tradotto in nome l'esigenza di combattere l'arbitrio del pubblico potere, di sottoporre al diritto il rapporto fra Stato e cittadino. Il processo di costituzionalizzazione si era identificato nel processo di smantellamento dello Stato assoluto e di edificazione dello Stato di diritto. Anche quando facevano riferimento ad istituti del diritto privato come la proprietà, le norme costituzionali restavano norme di diritto pubblico: esse giuridificavano il rapporto fra lo Stato e il proprietario; miravano, regolando i casi e le procedure di espropriazione, a sottrarre il secondo all' arbitrio del primo. "(in Diritto privato, 8. ed.. Padova, CEDAM, 1994, p. 46). 
liberdade e da igualdade, porém a Constituição possuia uma função limitada.

Em outras palavras: a Constituição era um texto pairando acima ou no topo do sistema jurídico, mas, em verdade, ineficaz.

Segundo as idéias da escola da exegese, os princípios e normas constitucionais seriam apenas uma diretriz política traçada para o futuro legislador; teriam caráter meramente programático, servindo de orientação de política legislativa, e só tendo efetiva vigência a partir da edição de norma de lei ordinária a respeito.

Tal enfoque, uma vez que retirava vigência à regra constitucional, do ponto de vista do próprio sistema jurídico acabou por ser visto como atentatório à hierarquia das normas constitucionais. ${ }^{15}$

A partir da Constituição de Weimar surgiu uma nova noção: uma Constituição que trata também dos direitos privados, voltada para o bem estar social e a justiça distributiva. ${ }^{16}$

Sociedade civil e Estado saem dos pólos opostos em que eram antes colocados.

Assim, as normas constitucionais passam a atuar como verdadeiras leis de direito privado, seja regulando diretamente as relações entre particulares, seja como orientação para a redação de leis ordinárias. ${ }^{17}$

A despeito disto, interpretações na linha do caráter meramente programático das cláusulas constitucionais em geral são muito presentes entre os doutrinadores, sendo ilustrativa, neste passo, a discussão a respeito

15 Sobre o asșunto, crítica de Rolando E. Pina à teoria sobre cláusulas programáticas, (in Cláusulas constitucionales operativas y programáticas - Ley fundamental de la República Federal de Alemania. Buenos Aires, ASTREA, 1973, p. 24-6).

16 A Constituição brasileira de 1988 corresponde ao "tipo weimeriano", sendo as duas palavras chaves para compreendê-la o intervencionismo e o protecionismo. (Gustavo Tepedino, in Contorni della proprietà nella Costituzione brasiliana del 1988, cit., p. 98).

17 Luis Roberto Barroso agrupa as normas constitucionais em três categorias: A. normas constitucionais de organização - que "traçam a estrutura do Estado"; B. normas constitucionais definidoras de direitos - "as que tipicamente geram direitos subjetivos," e C. normas constitucionais programáticas "veiculam princípios desde logo observáveis, ou traçam fins sociais a serem alcançados pela atuação futura dos poderes públicos." Sua noção de normas programáticas não corresponde, porém, à inefetividade atribuida pela doutrina tradicional às regras constitucionais, eis que "não geram direitos subjetivos na sua versão positiva, mas geram-nos em sua feição negativa." (in Princípios constitucionais brasileiros (ou de como o papel aceita tudo). Revista Jurídica Themis. Curitiba, n. 7 outubro/1991, p. 22-3).

Revista da Faculdade de Direito da UFPR, Curitiba, a. 29, n. 29, 1996, p. 147-172 
da existência, ou não, no direito positivo brasileiro, de uma lacuna no que se refere à proteção dos direitos de personalidade, tendo em vista o rol de direitos fundamentais do cidadão assegurados constitucionalmente. ${ }^{18}$

\subsection{A auto-aplicabilidade das normas constitucionais}

A Constituição traduz uma gama de forças políticas, um conjunto de posições ideológicas muitas vezes antagônicas, que conseguiram atingir um ponto de confluência num certo momento histórico, assim se projetando para o futuro. ${ }^{19}$

Neste sentido, as normas constitucionais têm uma característica plural, justificando-se a partir de certos estamentos sociais, ideológicos e políticos, traçando um modelo, que se pode ser criticado pela eventual exclusão ou omissão de determinadas realidades presentes na sociedade, traz em si um caráter polivalente, pelo conjunto de valores que a inspiraram (como a proteção ao meio ambiente, função social da propriedade, consagração da igualdade na família, regulação dos meios de produção).

Estas opções e diretrizes traçadas na Constituição prevalecerão por um lapso maior ou menor de tempo, dependendo, para tanto, de sua correspondência com os anseios da comunidade a que se dirigem.

A partir daí, e por um lado, a defesa do caráter unitário da realidade jurídica e portanto do ordenamento jurídico implica em que os princípios inspiradores e característicos contidos na Constituição estejam presentes em todos os ramos do direito, e, por outro, que a leitura das normas jurídicas

18 Orlando Gomes asseverou, a propósito: “Os aspectos ressaltados de alğuns direitos de personalidade testemunham sua relevância, encarecendo a necessidade de preenchimento da lacuna do Direito Positivo nacional, e justificando o interesse dos juristas pelo estudo de sua dogmática." (in Introdução ao direito civil, 11. ed.. Rio de Janeiro, Forense, 1995, p. 163-4).

Em sentido contrário, sustenta Michel Temer: "É importante observar que os direitos e garantias fundamentais previstos no art. $5^{\circ}$ têm aplicação imediata, segundo o comando expresso no $\S 1^{\circ}$ do aludido dispositivo."

“Significa, a nosso ver, que os princípios fundamentais ali estabelecidos podem ser invocados na sua plenitude, até que sobrevenha legislação regulamentadora, quando for o caso, de sua utilização. " (in Elementos de direito constitucional, 6. ed.. São Paulo, Ed. Revista dos Tribunais, 1989, p. 28).

19 No dizer de Miguel Reale, "Sendo uma categoria histórica, cabe reconhecer que nenhuma Constituição é separável do complexo de circunstâncias e conjunturas sociais, econômicas, demográficas, militares, em uma palavra, culturais, que condicionou a sua feitura, a começar pela atitude dos legisladores constituintes perante a realidade cuja organização e atividades tinham em vista determinar em seus elementos básicos." (in Aplicações da Çonstituição de 1988. Rio de Janeiro: Forense, 1990, p. 4) 
seja feita à luz do texto constitucional, uma vez que a distinção entre as normas constitucionais e ordinárias é traçada basicamente não no plano qualitativo, mas apenas no âmbito quantitativo. 20

Neste sentido, não tem pertinência a assertiva de que tal ou qual tema ou matéria não seja constitucional.

Esta colocação, no entanto, não é pacífica, opondo-se a ela a afirmação de que existiriam obscuridades ou um caráter de generalidade na norma constitucional impedindo ou dificultando sua aplicação aos casos concretos, como ocorre no argumento encontrável em nossa doutrina a respeito da função social da propriedade, em que se assevera que a inserção do princípio no texto constitucional gera dificuldades à sua auto-executoriedade. 21

Uma crítica desta ordem decorre de uma concepção excessivamente reducionista do direito, até em face da circunstância que foi a superação do positivismo que engendrou a crise das codificações a proliferação das leis especiais, mais adaptadas à complexidade e avanços tecnológicos e científicos do mundo atual, propiciando a revalorização do texto constitucional, como lei geral, garantidora de um direito igual para todos, tanto no sentido formal, quanto substancial. ${ }^{22}$

20 Pietro Perlingieri refere, sobre o assunto: "Sostenere l'unitarietà dell'ordinamento giuridico significa che i suoi princípi ispiratori e caratterizzanti sono presenti in ogni c.d. parte del diritto, mentre col proporre una netta distinzione tra ordinamento privatistico e pubblicistico si finisce con il contrapporre i princípi caratterizzanti l'una e l'altra branca del diritto. Sí che, definendo di diritto pubblico i princípi costituzionali, essi diventano estranei al c.d. diritto privato interamente fondato sul codice civile. L'impostazione, in sostanza, contribuisce a mantenere estranea ai rapporti civilistici la piú moderna esperienza socio-politica. Se invece si ha chiara l'unitarietà dell'ordinamento giuridico non si esiterà ad applicare anche ai rapporti civilistici i princípi fondamentali della costituzione." (in op. cit , p. 28).

21 Em conclusões de comunicação versando sobre a função social dos bens de produção, Fábio Konder Comparato formula a seguinte proposição: “A chamada função social da propriedade representa um poder-dever positivo, exercido no interesse da coletividade, inconfundível, como tal, com as restrições tradicionais ao uso de bens próprios. A afirmação do princípio da função social da propriedade, sem maiores especificações e desdobramentos, tem-se revelado, pela experiência constitucional germânica, tecnicamente falha." (in Direito empresarial - Estudos e Pareceres. São Paulo, Saraiva, 1990, p. 37 ).

22 A propósito, cabe citar Gustavo Tepedino: "La civilistica brasiliana, ancor'oggi, riserva alla normativa ordinaria una sorta di ruolo centrale nel processo interpretativo. La priorità e la indispensabilità della normativa ordinaria all'aplicazione della Costituzione sono proposizioni che si rifanno piú che mai inquietanti: la prima capovolge la gerarchia del sistema, "incorrendo nel frequente errore di leggere la Costituzione alla luce del codice, invvece di leggere il codice alla luce della Costituzione"; la seconda, "retaggio della concezione di tipo tradizionale", non sarebbe ormai che un mero pregiudizio." (in Contorni della proprietà nella Costituzione brasiliana del 1988, cit., p. 105).

Revista da Faculdade de Direito da UFPR, Curitiba, a. 29, n. 29, 1996, p.147-172 
Ante a crescente complexidade e divisão na sociedade, o desenvolvimento do direito dá-se em dois movimentos que se opõem e se completam.

A intervenção do Estado no domínio econômico, na proteção dos bens de interesse público, na ação cultural, paralelamente à sua atividade política evidencia um movimento no sentido da publicização do direito.

Em sentido contrário, dá-se a privatização de setores e inștitutos governados pelo Estado, em nome da maior flexibilidade dos mecanismos de direito privado para a obtenção de resultados úteis para a sociedade.

Isto não exclui, contudo, que ambos os mecanismos se baseiem em normas constitucionais, tendo em vista que, se a dicotomia direito público - direito privado foi produzida pela forma de sociedade em que vivemos, ${ }^{23}$ a alteração da realidade provồcou a crise desta distinção, com a inserção no texto constitucional de regras e princípios de conteúdo voltado para a regulação da vida do cidadão, conforme sua organização no contexto da realidade atual.

A conclusão a que se chega, a respeito, embora passível de contradição, é de que fonte real do direito, na qual se deve basear seu operador, é a Constituição. ${ }^{24}$

23 Michel Miaille afirma que “ A distinção-oposição entre direito público e direito privado não é, pois, 'natural': não é lógica em si, traduz uma certa racionalidade, a do Estado burguês. Assim, podem ser postas em funcionamento a ideologia e as instituições deste Estado como instância autónoma na formação social. A classificação não é estritamente e vagamente histórica: está ligada à história de uma sociedade que conheceu gradualmente a dominação do modo de produção capitalista. " (op. cit., p. 159).

24 Sobre as constituições na atualidade assevera Francesco Galgano: "La costituzione cessa di essere, anche se questa formula viene tuttora meccanicamente ripetuta, solo la fonte suprema del diritto pubblico, regolatrice della forma di governo e delle guarentigie di libertà dei cittadini nei confronti dello Stato; diventa, al tempo stesso, la legge fondamentale del diritto privato, regolatrice di rapporti fra privati, o con norme immediatamente precettizie o, più frequentemente, con norme di indirizzo per la legislazione ordinaria." (in op. cit., p. 47-8). 


\section{Mudança e transformação na Função da Constituição}

\subsection{A superação do sistema clássico e o fim do dogma da autonomia privada}

Não é apenas em Michel Miaille que encontramos a idéia da vinculação entre o modo de produção capitalista e a atribuição de personalidade a todos os homens. ${ }^{25}$ Bem pensados os mitos orientadores do liberalismo jurídico, não há como se fugir a esta conclusão.

A coincidência entre a passagem do feudalismo ao capitalismo e a atribuição de personalidade a todo ser humano, tornando a todos formalmente iguais e capazes de exercer uma vontade livre, no âmbito de sua autonomia privada, não é acidental.

A revalorização formal da pessoa, a atribuição igualitária de direitos de personalidade a qualquer indivíduo, com a conseqüente capacidade de direito e de fato, em verdade foi fundamental para a implantação do modo capitalista de organização da produção.

Em face do modelo econômico centrado no capital e na apropriação privada dos bens de produção, o homem livre e dotado de uma igualdade formal face a seus semelhantes poderia, no exercício de sua autonomia privada, contratar, obrigar-se nos contratos de trabalho ou celebrar validamente ajustes envolvendo alienação e troca de bens.

Se é fato que o direito único do trabalhador-despossuído acabava sendo o de vender sua força de trabalho e na troca de bens a parte economicamente mais forte sempre ficava em situação privilegiada, isto não foi suficiente para excluir o mito da autonomia privada na regulação das relações jurídicas.

25 Ana Prata assim coloca a questão: “A separação do trabalhador dos meios de produção, característica base do modo de produção capitalista, transforma aquele em mero detentor de força de trabalho, em mero trabalhador potencial, e os meios de produção em instrumentos parados se não combinados com aquela força de trabalho. A ligação entre o trabalhador e os meios de produção só é possível pelo acordo daquele e do proprietário destes. Declarado livre o trabalhador, isto é, reconhecida a propriedade do trabalhador à sua força de trabalho, isso impõe que lhe seja reconhecida personalidade jurídica e capacidade negocial, para que ele possa celebrar o contrato pelo qual aquela ligação se mediatiza, agora necessariamente." (in op. cit., p. 8). 
Do ponto de vista da sociedade liberal-capitalista, a importância do ter (a apropriação de bens) e a liberdade para contratar envolvem os aspectos fundamentais do direito à liberdade.

O negócio jurídico, do qual a forma mais característica é o contrato, é a afirmação da liberdade do indivíduo; é o efeito de sua vontade livre.

A noção de contrato, cujas características foram firmadas no Código de Napoleão, é fundamentalmente individualista.

$\mathrm{Na}$ abstração do modelo clássico do contrato, a autonomia privada é colocada no centro da atividade, de sorte a reduzir a importância de sua função na vida da sociedade.

Neste sentido, a autonomia dos indivíduos é mero instrumento jurídico de atuação, concretização e tutela de interesses privados, de onde o mito de que o contrato faz lei entre as partes e o poder público não interfere na vida contratual.

É bem verdade que o modelo liberal foi cedendo, do ponto de vista econômico, às necessidades de transformação da realidade, ainda que de forma gradual.

Esta foi provavelmente a forma de garantir sua sobrevivência, eis que, do ponto de vista ideológico, as transformações sempre foram mais difíceis de realizar.

Foi assim que a autonomia privada foi deixando de ser meio e instrumento de composição jurídica de interesses de natureza essencialmente individual, passando a ser ligada à função estabelecida no ordenamento jurídico para os contratos.

A partir deste ponto, a autonomia individual passa a ser inserida num certo contexto de realidade, em um determinado momento histórico.

26 Reza o artigo 1101 do Código Civil Francês: "Le contrat est une convention par laquelle une ou plusieurs personnes s'obligent, envers une ou plusieurs autres, à donner, à faire ou à ne pas faire quelque chose."

27 Em "Notas sobre o dirigismo contratual", comentou Miguel Reale, a propósito: "Com o advento do Código Civil francês, refletindo o triunfante sentido individualista da civilização burguesa, o contrato, expressão da autonomia das vontades e da coordenação dos direitos subjetivos, emergiu como instituto essencial ou mais relevante do ordenamento jurídico. "(in Temas de direito positivo. São Paulo, Ed. Revista dos Tribunais, 1992, p. 13). 
Em contradição com a neutralidade do Estado liberal, que via o interesse público apenas como a forma de assegurar melhores condições para o exercício e o desenvolvimento dos direitos privados (de onde a nítida separação entre as normas de direito público e as de direito privado), assim regulamentando as relações entre os cidadãos e o poder, a intervenção estatal na economia ocorrida ao longo do século XX excepcionou a concepção da autonomia privada, em nome das necessidades sociais e das desigualdades reais entre os indivíduos, enquanto sujeitos econômicos.

Neste sentido, deu-se a recodificação das noções de interesse público e autonomia privada, embora ainda sob a influência do individualismo. ${ }^{28}$

Conseqüência direta deste estado de coisas foi a já mencionada intervenção no exercício do direito de propriedade, que deixou de representar um interesse individual, egoístico, passando a ser vinculado ao interesse social; a circunstância de o contrato ter deixado de ser um ato de autonomia privada, ao menos em caráter de exclusividade e da família, de instituição privada, ter passado a um direito do cidadão.

Em decorrência da publicização do direito regulador das relações privadas e da privatização das normas aplicáveis à atividade do Estado, tornou-se menos nítida a distinção entre direito público e direito privado. ${ }^{29}$

$\mathrm{Na}$ medida em que o modelo liberal não conseguiu se manter adaptado à realidade econômico-social do século XX, a autonomia privada,

28 Em crítica aos fundamentos oitocentistas do sistema jurídico francês, no qual teria sido atualizado o conteúdo, mas a concepção das relações humanas continuaria sendo a mesma, Maurice Gaillard assevera, a respeito do mito do interesse geral: 'L'intérêt général (il peut s'appeler aussi intérêt public, ou encore utilité publique) fournit à l'État qui est censé n'agir qu'en son nom um certain nombre de justifications..."

Em seguida, a respeito das funções deste mito : “L'intérêt général fournit le symbole de l'unité et du bien-fondé de l'ordre social. Il implique que les antagonismes sociaux sont surmontés et qu'il est possible de définir un intérêt commun à tous les individus." (in L'intelligence du droit. Paris, Les Éditions d'Organisation, 1992, p. 87).

A unidade social sendo a expressão de um sentimento de participação, necessário à perpetuação da sociedade, conclui Gaillard: "L'État devient ainsi la représentation indispensable de l'unité sociale, la référence exprimant l'identité de la société. C'est le lieu, l'instance de synthèse des volontés disparates et de définiton de l'intérêt général." (in op. cit., p. 88)

29 Sobre as mutações na distinção entre direito público e direito privado a partir das variantes de tempo e lugar e conforme as tendências sociais e políticas, asseverou Alberto Trabucchi: "Nell'era in cui viviamo, in corrispondenza con l'orientamento verso forme piú sociali, anche il mondo giuridico è venuto acquistando un sostanziale diverso significato per la maggior rilevanza riconosciuta agli interessi collettivi e per il piú forte rispetto che si sente dovuto alla società di tutti gli upmini." (in Istituzioni di Diritto Civile, 20 ed., Padova, CEDAM, 1978, p. 9). 
instrumento por excelência da concepção liberal do direito, entrou em crise, como não poderia deixar de ser.

A partir daí, o mito da autonomia dos indivíduos foi atingido, passando a sofrer limitações e restrições, através da intervenção nos contratos - manifestada nas suas mais variadas formas, seja a partir da determinação do conteúdo ou de elementos típicos do ajuste, seja em face da perda da liberdade de escolha da outra parte ou da liberdade de contratar - na atividade econômica e nas formas de apropriação de bens, muitas vezes operacionalizada através de normas constitucionais, ${ }^{30}$ o que não deixa necessariamente de refletir a personalização do direito (e de ser um resquício do individualismo), em paralelo com o pluralismo social.

Por outro lado, a tutela da personalidade em termos substanciais ocasionou uma série de soluções na linha da valorização do ser em confronto com o ter, como ocorre na sobredita função econômico-social ora atribuida aos contratos, em decorrência da superação da igualdade formal no plano da realidade, e na proteção de um patrimônio mínimo ao cidadão. ${ }^{31}$

Paralela e de certa forma contraditoriamente a isto, não há como se ignorar hoje a discussão fundamental a propósito da incompatibilidade entre o próprio sistema social, com seu direito centrado no homem, e o meio ambiente, tendo em vista que suas realizações não raro (e pode-se dizer até que muitas vezes) envolvem desrespeito às leis da natureza - físicas, biológicas, termodinâmicas, e todas as que se possa recordar.

30 Luis Diez-Picazo considera a Constituição espanhola ponto de referência do fundamento da autonomia da vontade, o que, se não a torna individualista, do ponto de vista ideológico, pelo menos revela a tendência ao personalismo, afirmando:... "resulta claro que en la actualidad la fundamentación del principio de autonomía privada hay que buscarla en la Constitución. Y habrá que confesar, a renglón seguido, que no es fácil la búsqueda de tal punto de entronque. La libertad de contratación y la interdicción de los contratos forzosos se ha querido encontrar en el artículo 38 de nuestra Constitución. La verdad es que por la vía del citado art. 38 volveremos a encontrar una libertad contractual con un contenido de carácter netamente económico."

"Aunque no sea posible el encuentro cabal de un precepto concreto, no es difícil atisbar tal cúmulo de datos, que hagan suponer que la autonomía privada, como principio del Derecho, se encuentra implícita en la Constitución de 1978."

"Aunque no se pueda hablar de ideología individualista al cien por cien en el texto constitucional, aparece claro por lo menos el personalismo. "(in Familia y derecho. Madrid, Editorial Civitas, S.A., 1984, p. 91).

31 Numa perspectiva compatível com a superação da dicotomia direito civil - direito público em matéria de proteção da personalidade, refere Pietro Perlingieri: "Il valore della persona non è piú espresso soltanto in termini speculativo-filosofici, ma in proposizioni politiche, giuridiche ed anche d'interesse prevalentemente economico. "(in La personalità umana nell' ordinamento giuridico. Camerino, Jovene editore, 1972, p. 45). 
Há quem conclua, a respeito, que a biotecnologia e a engenharia genética estão matando a vida. ${ }^{32}$

Considerando-se que a personalidade, a capacidade de direito são dados gerados pelo próprio sistema jurídico (de tal sorte que se poderia recusar - como já se negou ao longo da História - atributos de personalidade a determinados seres humanos), nada impede, neste sentido, que se passe a subjetivar, ${ }^{33}$ com amplitude cada vez maior, a proteção da vida - não apenas do homem - mas também do meio que o cerca.

\subsection{A ordinarização da Constituição}

A norma constitucional não é regra a ser respeitada apenas pelo legislador ordinário e operada exclusivamente pelos ministros do Supremo Tribunal Federal, mas é valor, princípio, norma, a ser aplicada por qualquer operador do direito, assim dando uma resposta mais compatível com o contexto histórico-político-econômico-social para os conflitos de interesses suscitados.

Não obstante este ponto de vista cada vez mais se impor, ainda existem críticos à constitucionalização de temas do direito civil, ${ }^{34}$ ou à ordinarização da Constituição.

32 "La complessità del sistema antropico, o se si preferisce, del sistema sociale e la complessità del sistema ambiente non sono compatibili oltre una certa soglia. La complessità del sistema sociale vive a scapito della complessità del sistema ambiente. L'idea che il sistema sociale possa controllare l'impatto ambientale incorporando ambiente è un'idea certamente sugestiva, anche se non nuova. In termini lingusitici è indubbiamente una invenzione che non so quanto meriti coltivare per chi ne abbia voglia. La verità è che le biotecnologie combinate con le ingegnerie genetiche stanno producendo, quanto meno, estinzione di specie: uccidono la vita e si dica pure che riducono la complessità ambientale." (PALAZZO, Agostino, in "La tematica ambientale e i diritti umani", in LIPPOLIS, Ĺaura (org.). Diritti umani, poteri degli stati e tutela dell'ambiente. Milano, Giuffrè, 1993, p. 90-1).

33 A expressão é de Michel Serres: "A natureza se conduz como um sujeito." (in O contrato natural. Rio de Janeiro, Editora Nova Fronteira, 1991, p. 49.).

34 Celso Bastos, discorrendo sobre os direitos e garantias individuais na Constituição Brasileira de 1988, assevera que... "Não devemos nos impressionar com a abundância desses artigos, porque na grande maioria eles são artigos que fariam parte e que faziam realmente parte do Código Civil, do Código Penal e de outros códigos do nosso Direito. Foram pura e simplesmente transcritos. Não sei porque. Isso não causa uma vantagem, um benefício, nem para o Direito Civil, nem para o Direito Constitucional. Porque constitucionaliza essas matérias, lhes dá um rigor que na verdade elas dispensam. São matérias muito mais apropriadas para desalojarem, dentro dos códigos de Direito Constitucional, mas foram guindadas realmente a um aceito constitucional. Então, aqui não posso deixar de fazer uma crítica, ${ }^{\sim}$ com toda objetividade. Não é com veemência. É com espírito bastante neutro. Para mim isto atendeu a um espírito demagógico. Daí procurar, de alguma maneira, dar idéia de que se está fortalecendo o indivíduo contra o Estado." "Direitos e garantias individuais", in A Constituição Brasileira - 1988 - Interpretações - II Fórum Jurídico. Rio de Janeiro, Forense Universitária, 1988, p. 21-32, p. 23). 
Paralelamente a isto, há a preocupação, ainda mantida por muitos doutrinadores, com a regulamentação por lei ordinária das normas contidas na Constituição.

É interessante observar que a aceitação da Constituição como fundante da redação das leis ordinárias, ${ }^{35}$ lida como um documento hierarquicamente superior, a partir da noção de sistema jurídico, em verdade não se incompatibiliza com a visão da doutrina tradicional no sentido de que continua a demandar a regulamentação das disposições constitucionais pelo legislador ordinário, desta sorte não solucionando as questões que exigem a auto-aplicabilidade de normas constitucionais. ${ }^{36}$

Pelo contrário: este ponto de vista pode conduzir à afirmação de que haveria insegurança jurídica na prolação de decisões judiciais fundamentadas apenas em princípios e normas constitucionais, e à conclusão de que existiriam lacunas no ordenamento jurídico quando estes princípios e regras aplicados pelo poder judiciário não se encontram traduzidos em textos de lei ordinária. ${ }^{37}$

Uma objeção desta ordem segue a linha de pensamento de Franz Wieacker, ${ }^{38}$ em sua crítica ao direito judicial alemão do século XX, na qual,

35 Cabe citar, a respeito, José Lamartine Corrêa de Oliveira e Francisco José Ferreira Muniz: "Consideradas as fontes do direito como modos de formação ou de revelação do direito - portanto em sentido técnico-jurídico-formal-, diremos que os princípios fundamentais do Direito de Família estão enunciados ou são deduzidos das normas Constitucionais. Assim, por exemplo, as imposições constitucionais de igualdade entre homens e mulheres (art. $226, \S 5^{\circ}$ ) ou entre filhos nascidos dentro e fora do casamento (art. $227, \S 4^{\circ}$ ). Ao legislador ordinário cabe a tarefa de concretizar esses princípios fundamentais. (in Direito de família: Direito matrimonial. Porto Alegre, Sérgio Antonio Fabris Editor, 1990, p. 18).

36 Na já referida “A repersonalização das relações de família”, Paulo Luiz Neto Lôbo afirmou, nesta linha: "Além dos direitos fundamentais, que são de aplicação imediata, a Constituição cercou-se de mecanismos que viabilizam a eficácia de suas normas, podendo ser utilizados no âmbito do direito de família."

"Um deles é a inconstitucionalidade por omissão. Omissão do legislador, quando deva regulamentar a norma constitucional e não o faz..." (op. cit., p. 77).

37 Em conclusões de conferência a respeito da modificação dos modelos teóricos de família e do casamento introduzidos pela Constituição de 1988 referiu-se Francisco José Ferreira Muniz ao "vazio normativo como resultado da caducidade por inconstitucionalidade superveniente de inúmeras normas do direito de família anterior, contrárias à Constituição." (in O direito de família na solução dos litígios. Conferência proferida no XII Congresso Brasileiro de Magistrados (Belo Horizonte, 14 a 16 de novembro de 1991), separata, 23 p., Curitiba, 1992, p. 21).

38 Segundo Wieacker, "Toda a ruptura direta da jurisprudência em direcção à função social é necessariamente paga com a destruição do sistema, com a reformulação dos conceitos, com o abuso ou abandono dos sistemas construtivos."... (in História do direito privado moderno. Lisboa, Fundação Calouste Gulbenkian, 1980, p. 627). E adiante: "Se, na época do juiz positivista, a adesão firme às tradições e construções sistemáticas e conceituais foi censurada por prejudicar soluções realistas, hoje expomo-nos antes à censura de praticar um modo de julgar orientado por uma justiça experimentalista e desprovida de princípios básicos." (op. cit., p. 627). 
embora atribuindo aos tribunais superiores o mérito e a responsabilidade da evolução do direito germânico neste século, ressalta que, se esta evolução teve o mérito da superação do positivismo, trouxe consigo o risco da falta de segurança jurídica.

Por outro lado, a abordagem, pela Constituição Federal, de temas como a família, a propriedade e a autonomia privada, que tradicionalmente se considerava conteúdo do direito civil, chega a ser vista como um sinal de desprestígio, diminuição, ou declínio do direito privado, ${ }^{39}$ o que nada mais é do que a conseqüência de uma visão compartimentalizada do direito, de tal sorte a não se admitir, neste caso, sequer a interdisciplinariedade no âmbito interno do sistema jurídico.

$\mathrm{Na}$ vertente oposta, encontra-se na doutrina o reconhecimento da interdisciplinariedade, em sentido amplo, na análise do fenômeno jurídico, seja a partir da consideração do direito - ciência social - como tal inserido num contexto sócio-político-econômico, ${ }^{40}$ seja em face das preocupações dos estudiosos com o próprio futuro da humanidade, ${ }^{41}$ ou de uma visão

39 Esta é a opinião de Paulo Bonavides: “Tendo-se dilatado na sociedade o círculo de ingerência do Estado - que entrou a disciplinar esferas das quais, dantes, ainda em nome do Direito Natural, fora, em larga parte, expungido, como no caso do direito de propriedade - verificou-se sensível declínio de certos institutos fundamentais de Direito Privado, em proveito da influência crescente, se não avassaladora, que o Direito Constitucional começou, ali, a exercer."

"Interesses, há menos de meio século, reputados exclusivamente individuais e aparentemente intangíveis tomaram, com o tempo, notável transcendência social, ocasionando, como efeito, sua ordenação subsequente pelo Direito Constitucional." (in Curso de direito constitucional, 5. ed., São Paulo, Malheiros, 1994, p. 34).

40 Em matéria de direito de família são facilmente encontráveis assertivas como a de Alain Bénabent: “Quant au fondement du droit de la famille, il résulte essentiellement de l'état sociologique de la population à régir. Plus que toutes les autres branches juridiques, ce droit est dépendant des bouleversements sociologiques. Il est directement influencé par les conceptions morales, ainsi que par les conceptions religieuses qui sont en vigueur dans une population à un moment donné. Il ne faut pas oublier à cet égard que, sous 1 'Ancien Droit, le droit de la famille était une matière qui ne dépendait pas de l'autorité publique mais de l' autorité ecclésiastique, de sorte qu'il se confondait purement et simplement avec la doctrine religieuse en la matière." (in Droit civil - La famille. Paris, LITEC, 1982, p. 9).

41 Nesta linha de preocupação, Antonio Tarantino lembra que "i diritti umani, i diritti degli anilmali e quelli dell'ambiente sono in una situazione di continuo pericolo; sono spesso violati e spesso non trovano alcuna tutela perché la comunità scientifica, e non di rado quella politica, subordinano i diritti umani ai diritti della scienza."

"Pertanto, stante il prevalere di tale modo di intendere la libertà della comunità scientifica, non si può avere esitazione alcuna ad affermare che gli scienziati, i politici e le forze plutocratiche sono $i$ veri responsabili della situazione in cui versano i diritti della vita, in senso ampio intesa, sul pianeta Terra." (in Diritti umani, progresso scientifico e tutela dell'ambiente, cit., p. 117).

Revista da Faculdade de Direito da UFPR, Curitiba, a. 29, n. 29, 1996, p. 147-172 
voltada para a pluralidade do direito, no sentido de sua historicidade e importância na realidade social. ${ }^{42}$

Há os autores que reconhecem a evolução que representa, em termos de repersonalização dos institutos jurídicos, a inserção de normas que, por seu conteúdo, seriam consideradas pela dogmática jurídica como normas de direito privado no texto constitucional, ressaltando sua conotação de interesse público. ${ }^{43}$

No processo de constitucionalização, o direito privado alarga seu campo de atuação. ${ }^{44}$

As disposições constitucionais acerca dos direitos e deveres fundamentais dos cidadãos, da propriedade, da família, da atividade econômica, não dizem respeito apenas às relações entre os cidadãos e o Estado, mas às relações das pessoas entre si.

O legislador ordinário não é o destinatário único das normas constitucionais. Os direitos e deveres extraídos destas regras aplicam-se às pessoas, naturais e jurídicas e, neste sentido, sua eficácia não deve ser considerada menos direta e cogente que as das leis ordinárias, relativamente às quais, inclusive, no plano do próprio sistema jurídico, ocupam um posição de preeminência.

Se é fato que as normas constitucionais são muitas vezes formuladas em termos mais gerais, isto não exclui sua auto-aplicabilidade, ainda que a

42 Pietro Perlingieri, já na década de setenta, situava amplamente a questão: "Lo studio del diritto - e quindi anche del diritto tradizionalmente definito 'privato' - non può prescindere dall' analisi della società nella sua storicità locale e universale, sí da consentire l'individuazione del ruolo e del significato della giuridicità nell'unitarietà e complessità del fenomeno sociale. In questa prospettiva la Facoltà di giurisprudenza è una facoltà di studi sociali avente per oggetto di ricerca e di didattica gli aspetti economici e sociologici, tradizionali e consuetudinari, psicologici e biologici, normativi e convenzionali della realtà. La giurisprudenza è scienza sociale bisognosa di sempre maggiori aperture, necessariamente sensibile a qualsiasi modificazione della realtà intesa nella sua piú ampia accezione." (in Profili istituzionali del diritto civile, cit., p. 1).

43 Neste sentido, E. Roppo e M. Scaparone destacam ser a Constituição italiana fonte importantíssima do direito privado (op. cit., p. 324); José da Costa Pimenta sustenta a aplicação direta dos princípios estabelecidos na Constituição portuguesa em matéria de filiação (in Filiação. Coimbra, Coimbra Editora, 1986, p. 9 e segtes.).

44 Luiz Edson Fachin assevera que: “A partir de 1988, em suma, há constitucionalização da família e do casamento, ao mesmo tempo em que o legislador constitucional chamou para si a tarefa de estabelecer as linhas mestras do sistema jurídico atinente à filiação. O Código Civil perde, a partir daí, o papel de lei fundamental diante das regras agora constitucionalmente estatuídas." (in Estabelecimento da filiação e paternidade presumida. Porto Alegre, Sérgio Antonio Fabris Editor, 1992 , p.59). 
interpretação, neste caso, exija um maior cuidado do operador do direito, que deve considerar as condições interdisciplinares que determinaram a edição da regra (os aspectos históricos, ideológicos, econômicos, sociais, éticos, dentre outros, que nortearam sua redação).

Significativa a propósito é a leitura referente à igualdade jurídica em matéria de família: a igualdade substancial, correspondente à visão atual do direito, requer um tratamento igual de situações iguais e um tratamento desigual para hipóteses desiguais. Uma interpretação da norma a partir de um nivelamento sistemático de situações diversas contraria o princípio da igualdade consagrado na Constituição Federal. ${ }^{45}$

Independente das divergências suscitadas, é inarredável que a Constituição deu um salto qualitativo para o futuro ao repersonalizar e funcionalizar os institutos fundamentais do direito privado. Neste sentido se tornou a lei básica em matéria de direito civil, à luz da qual devem ser lidas, no plano jurídico, as realidades da vida.

\section{BIBLIOGRAFIA}

ARNAUD, André-Jean. O direito traído pela filosofia. Porto Alegre, Sérgio Antonio Fabris Editor, 1991.

BARROSO, Luís Roberto. Princípios constitucionais brasileiros (ou de como o papel aceita tudo). Curitiba, Revista Jurídica Themis (7):17-39, outubro 1991.

BASTOS, Celso. Direitos e garantias individuais. In: A Constituição Brasileira - 1988 Interpretações - II Forum Jurídico. Rio de Janeiro, Forense Universitária, 1988.

BÉNABENT, Alain. Droit civil. La famille. Paris, LITEC, 1982.

BITTAR, Carlos Alberto (coord.). O direito de família e a Constituição de 1988. São Paulo, Saraiva, 1989.

45 Cf. Francisco José Ferreira Muniz: "Se o conteúdo jurídico-constitucional do princípio da igualdade proíbe diferenciações de tratamento ilegítimas, exige que a igualdade não seja puramente formal ou mecânica - para que as diferenças objetivas que sejam significativas e relevantes (portanto, fundadas sobre motivos sérios), justifiquem um tratamento desigual."

"A obrigação de diferenciação é; portanto, uma dimensão do conteúdo jurídico-constitucinal do princípio da igualdade, para compensar desigualdades fáticas de natureza econômica, social e cultural." (in $\mathrm{O}$ direito de família na solução dos litígios, cit., p. 10).

Revista da Faculdade de Direito da UFPR, Curitiba, a. 29, n. 29, 1996, p.147-172 
BOBBIO, Norberto \& PIERANDREI, Franco. Introduzione alla costituzione. Bari, Laterza, 1982.

BONAVIDES, Paulo. Curso de direito constitucional. 5. ed., São Paulo, Malheiros, 1994.

CARBONNIER, Jean. Flexible droit - Pour une sociologie du droit sans rigueur. 7. ed., Paris, Librairie Generale de Droit et de Jurisprudence, 1992.

CLÈVE, Clémerson Merlin. Temas de Direito Constitucional (e de Teoria do Direito). São Paulo, Editora Acadêmica, 1993.

COMPARATO, Fábio Konder. Direito empresarial: Estudos e pareceres. São Paulo, Saraiva, 1990.

CORRADINI, Domenico. Storicismo e politicità del diritto. Bari, Laterza, 1974.

CUNHA, Paulo Ferreira da. Introdução à teoria do direito. Porto, RÉS-Editora.

CUNHA, Paulo Ferreira da. Sociedade e Direito - Quadros institucionais, Porto, RÉS-Editora.

DIEZ-PICAZO, Luis. Familia y derecho. Madrid, Editorial Civitas, S.A., 1984.

FACHIN, Luiz Edson. Estabelecimento da filiação e paternidade presumida. Porto Alegre, Sérgio Antonio Fabris Editor, 1992.

FACHIN, Luiz Edson. Limites e possibilidades da nova teoria geral do direito civil. In: Jurisprudência Brasileira. Curitiba, Juruá, (174):45-50, 1994.

GAILLARD, Maurice. L'intelligence du droit. Paris, Les Éditions d'Organisation, 1992.

GALGANO, Francesco. Diritto privato. 8.ed, Padova, CEDAM, 1994.

GÉRARD, Philippe. Droit, égalité et idéologie. Contribution à l'étude critique des principes généraux du droit. Bruxelles, Publications des Facultés Universitaires Saint-Louis, 1981. 
GOMES, Orlando. Introdução ao direito civil. Rio de Janeiro, Forense, 1995.

GOMES, Orlando. Transformações gerais do direito das obrigações. 2. ed., São Paulo, Ed. Revista dos Tribunais, 1980.

LIPPOLIS, Laura (org.). Diritti umani, porteri degli stati e tutela dell'ambiente. Milano, Giuffrè, 1993.

LUCHAIRE, François. Les fondements constitutionnels du droit civil. In: Revue Trimestrielle de Droit Civil, Paris (2): 245-328, avril-juin 1982.

MIAILLE, Michel. Introdução crítica ao direito. Lisboa, Editorial Estampa, 1989.

MUNIZ, Francisco José Ferreira. O direito de família na solução dos litígios. Conferência proferida no XII Congresso Brasileiro de Magistrados (Belo Horizonte, 14 a 16 de novembro de 1991). separata, Curitiba, 1992.

OLIVEIRA, José Lamartine Corrêa de, MUNIZ, Francisco José Ferreira. Direito de Família (Direito matrimonial). Porto Alegre, Sérgio Antonio Fabris Editor, 1990.

OPPO, Giorgio. Diritto privato e interessi pubblici. In: Rivista di diritto civile. Gennaio-Febbraio, 1994:25-41.

PERLINGIERI, Pietro. La personalità umana nell'ordinamento giuridico. Camerino, Jovene editore, 1972.

PERLINGIERI, Pietro. Profili istituzionali del diritto civile. Camerino, Jovene editore, 1975.

PIMENTA, José da Costa. Filiação. Coimbra, Coimbra Editora, 1986.

PINA, Rolando E. Cláusulas constitucionales operativas y programáticas Lei fundamental de la República Federal de Alemania. Buenos Aires, ASTREA, 1973.

PINTO, Carlos Alberto da Mota. Teoria geral do direito civil. Coimbra, Coimbra Editora, Limitada, 1993.

PRATA, Ana. A tutela constitucional da autonomia privada. Coimbra, ALMEDINA, 1982. 
REALE, Miguel. Aplicações da Constituição de 1988. Rio de Janeiro, Forense, 1990.

REALE, Miguel. Temas de direito positivo. São Paulo, Ed. Revista dos Tribunais, 1992.

ROPPO, E., SCAPARONE, M.. Diritto pubblico e diritto civile. Bari, Editori Laterza, 1985.

SERRES, Michel. O contrato natural. Rio de Janeiro, Editora Nova Fronteira, 1991.

TEMER, Michel. Elementos de direito constitucional, 6. ed.. São Paulo, Ed. Revista dos Tribunais, 1989.

TEPEDINO, Gustavo. Contorni della proprietà nella Costituzione brasiliana de1988. In: Rassegna di diritto civile, diretta da Pietro Perlingieri. Edizioni Scientifiche Italiane, (1):96-119, 1991.

TOBEÑAS, José Castan. Humanismo y derecho. Madrid, REUS, 1962.

TOBEÑAS, Jose Castan. Situaciones juridicas subjetivas. Madrid, REUS, 1963.

TRABUCCHI, Alberto. Istituzioni di diritto civile. 20. ed., Padova, CEDAM, 1978.

TRIMARCHI, Pietro. Istituzioni di diritto privato. 6. ed., Milano, Giuffrè, 1983.

WEILL, Alex, TERRÉ, François. Droit civil. Les personnes. La famille. Les incapacités. 5. ed., Paris, Dalloz, 1983.

WIEACKER, Franz. História do direito privado moderno. Lisboa, Fundação Calouste Gulbenkian, 1980. 